\title{
What is anthropology's object of study?
}

\section{A counterresponse to Schielke and Deeb}

\author{
Nadia FADIL, KU Leuven \\ Mayanthi FERnANDo, University of California, \\ Santa Cruz
}

Counterresponse to Meditations by Samuli Schielke and Lara Deeb on Fadil, Nadia and Mayanthi Fernando 2015. "Rediscovering the 'everyday' Muslim: Notes on an anthropological divide." HAU: Journal of Ethnographic Theory 5(2): 59-88

In their thoughtful and careful responses, both Lara Deeb and Samuli Schielke acknowledge some of the problems with the framework of everyday Islam that we identify in our text but also warn against an overly unifying treatment of the literature on everyday Islam. Our response will not rehash our arguments; rather, we will highlight the methodological process through which our essay took shape and then return to what we believe is an essential point of disagreement that pertains to anthropology's object of study.

1. This essay took shape as we witnessed how the question of the "everyday" became an increasingly prominent focus for the study of Islam within (and outside) anthropology and was often counter-posed to the recent focus on piety and ethical self-transformation. In this shift, Samuli Schielke's work was often posited as a central reference, and our decision to concentrate primarily on his essays was triggered by their impact in steering the conversation in this particular direction within the anthropology of Islam. The publication of Schielke's book in the spring of 2015 (well after the initial draft of our essay 
was completed) compelled us to reconsider some of the points we made, and we have added footnotes in those instances where Schielke's essays and his monograph diverge. However, many of the concerns we had regarding his juxtaposition between "religious" and other societal domains (such as economy, love, or social justice) remain in the monograph, as does Schielke's diagnosis of Salafism as an unnatural way of living one's life, as impelled by personal crisis, and as inherently unstable and transient (as illustrated through the figures of Mustapha, Nagat, and Fouad).

2. A central aim in our essay was to try to account for how the concept of the everyday functions in scholarship on Islam and what its effects are. We do not suggest that there exists a literature on the everyday that is unified in its orientation or in its approach. Rather, we tried to show how this concept of the everyday (or everyday life) has been articulated in these various scholarly works (with their admittedly very distinct theoretical orientations) primarily as a site of contestation and ambiguity. We also tried to show how, at least for certain scholars, this has the concomitant result of excluding those life-forms not seen as demonstrating a similar degree of ambiguity or complexity. As we argued, these life-forms - represented by the figure of the Salafi-are presented as unreal, unnatural, and ideologically driven. Our argument is not that all anthropologists who use the frame of everyday Islam similarly exclude revivalists from the realm of the human but rather that when the everyday functions as a marker of human similitude, and when the everyday is counter-posed to selfdisciplinary piety, the banishment of "fundamentalists" from the realm of the human is ever-present.

3. As we state in our essay, we do not argue against the analytic of the everyday. But what is this everyday other than the site of human interaction, anthropology's primary focus of analysis? Furthermore, what is not the everyday? It is indeed hard to imagine any situation mediated by human interaction that would not be part of the everyday. Are objects part of everyday life? Animals? Plants? Angels? Miracles? (After all, one of the discipline's commitments has been to include the realm of the invisible and the nonhuman in the everyday.)

4. A more substantive disagreement concerns what Schielke describes in his response as his commitment to complexity and tragic pursuit, which brings us to the kind of analytical work we do. Complexity, in our own work, is not an object of study in itself but rather part of a broader analytical focus on the ways in which individuals try to constitute themselves into legible social beings. This means attending to the practices, vocabularies, and bodily gestures that are (un) consciously adopted in trying to do so. The complexities of everyday life are an intrinsic part of this. Whether it concerns a Muslim in Burkina Faso who struggles to meet the daily requirement to pray (Debevec 2012), or a Muslim in Belgium who doesn't fast: these practices are, each in their own way, constitutive of ethical self-formation, and often in a manner that is neither easy nor straightforward (see Fadil 2009). Let us turn to the case of sexuality to illustrate our point more carefully. While a conflicting relationship has traditionally been assumed between sexual pleasure and religious orientation, a large body of 
literature has deconstructed such an assumption by showing how religious traditions like Islam have accommodated and even promoted sexual pleasure, usually within the framework of heterosexual marriage. Yet, in the context of modernity where sexuality exists independently from marriage and is considered integral to what it means to become a full subject (Foucault 1978), it becomes interesting to examine how the norm of being sexual (of sexual being) is navigated and negotiated within one's ethical life. Does it exist and is it lived in the same way for individuals who consider themselves committed Muslims? How is it experienced in an ethical world in which polygamous marriages are also considered an option (Fernando 2014)? How is the question of sexual pleasure navigated by those who are unmarried or nonheterosexual and who hold a commitment to the religious tradition? How does the latter affect the ways in which these Muslims see themselves? What kind of tensions does it produce? Do these Muslims consider themselves as less of a full subject for not having an active sexual life? Or does sexuality belong to the realm of personal and affective aphasia? Is sexual pleasure enacted through different means? Are these considered halal, makruh, or haram? How do these subjects navigate acts they view as zina (promiscuous), and how do they live through these apparent contradictions? Which acts are considered zina? And what is the status of zina in comparison with other acts that are considered illicit (such as lying, cheating, etc.)? To what extent is there a process of normalization of those acts that are considered illicit by the tradition? How does this occur at an individual or a social level, and to what extent does it result in a new conception of the (Muslim) self?

Our point is that examining the entanglements between ethical selfhood, concrete praxis, and (religious or secular) norms is not a straightforward process, and in that we share the commitment of Schielke and Deeb to consider the complexities of ethical lives. Yet taking up these complexities does not mean dislocating them from norms. Complexities only become meaningful against the backdrop of normative entanglements. This is not only an essential feature of social life. It is an essential characteristic of what it means to become a meaningful human subject.

\section{References}

Debevec, Liza. 2012. "Postponing piety in urban Burkina Faso: Discussing ideas on when to start acting as a pious Muslim." In Ordinary lives and grand schemes: An anthropology of everday religion. Vol. 18. EASA Series. New York: Berghahn Books.

Fadil, Nadia. 2009. "Managing affects and sensibilities: The case of not handshaking and not fasting." Social Anthropology 17 (4): 439-54.

Fernando, Mayanthi L. 2014. "Intimacy surveiled: Religion, sex, and secular cunning." Signs: Journal of Women in Culture and Society 39 (3): 685-708.

Foucault, Michel. 1978. History of sexuality: An introduction. Translated by Robert Hurley. Vol. 1. 3 volumes. New York: Pantheon Books.

Nadia Fadil

Anthropology Department 
Interculturalism, Migration, and Minorities Research Centre

KULeuven

Parkstraat 45-Box 3615 3000 Leuven, Belgium

Nadia.Fadil@soc.kuleuven.be

Mayanthi L. Fernando Anthropology Department 361 Social Science 1

University of California, Santa Cruz 1156 High Street, Santa Cruz, CA 95064 USA mfernan3@ucsc.edu 